\title{
Dose-Dense Chemotherapy: Principles, Clinical Results and Future Perspectives
}

\author{
Marc L. Citron \\ Albert Einstein College of Medicine, Bronx, New York, USA
}

\author{
Key Words \\ Breast cancer - Adjuvant chemotherapy - Anticancer \\ drug combinations - Neutropenia - Doxorubicin . \\ Paclitaxel · Filgrastim · Dose-dense therapy
}

\section{Summary}

The dose intensity of adjuvant chemotherapy for breast cancer is an important predictor of clinical outcome. Dose-dense chemotherapy increases the dose intensity of the regimen by delivering standard-dose chemotherapy with shorter intervals between the treatment cycles. The rationale for dose-dense therapy stems from the Norton-Simon hypothesis: Sequential, consecutive dosing of chemotherapy using single or a combination of agents increases the dose density over alternating dosing, improving results. Supporting adjuvant studies, such as C9741, and the ensuing clinical experience indicate an improved disease-free and overall survival. Dosedense adjuvant chemotherapy improves clinical outcomes without increasing toxicity.

\section{Introduction}

Patients and clinicians must weigh the risks and benefits of different postoperative breast cancer treatment options. Adjuvant chemotherapy aims to deliver a planned course of each drug based on a curative goal. The toxicity of this chemotherapy often necessitates dose reductions, at the possible expense of efficacy. The resulting risk of treatment failure from dose reductions and delays has serious repercussions and has been described as 'killing with kindness' [1].

\section{Schlüsselwörter}

Brustkrebs - Chemotherapie, adjuvant - KombinationsChemotherapie - Neutropenie - Doxorubicin - Paclitaxel . Filgrastim · Dosisdichte Therapie

\section{Zusammenfassung}

Die Dosisintensität einer adjuvanten Chemotherapie gegen Brustkrebs ist ein wichtiger Indikator des klinischen Effekts. Dosisdichte Chemotherapie erhöht die Dosisintensität des Behandlungsregimes, indem die Standarddosis-Chemotherapie in kürzeren Intervallen zwischen den Behandlungszyklen angewendet wird. Das Grundprinzip der dosisdichten Therapie basiert auf der Norton-Simon-Hypothese: Serielle, aufeinanderfolgende Dosierung der Chemotherapie mit einzelnen oder kombinierten Wirkstoffen erhöht die Dosisdichte gegenüber der alternierenden Dosierung und verbessert so das Ergebnis. Unterstützende adjuvante Studien, wie z.B. C9741, und die daraus folgenden klinischen Erfahrungen zeigen ein verbessertes krankheitsfreies und Gesamtüberleben. Dosisdichte adjuvante Therapie verbessert den klinischen Effekt, ohne die Toxizität zu erhöhen.

Dose intensity is a measure of chemotherapy delivery that looks at the amount of drug delivered per unit time (measured as $\mathrm{mg} / \mathrm{m}^{2} / \mathrm{wk}$ ) [1]. The relative dose intensity of a single-drug regimen can be expressed as the ratio of its dose intensities in test and standard regimens. Average relative dose intensity is calculated by averaging the relative dose intensity of each drug in a test regimen. A further refinement looks at the dose responses of individual drugs, calculates their unit dose intensities, and then combines them so that 'summation dose intensity' [2] can be obtained for any drug regimen. This approach 
can be used to compare and refine chemotherapy regimens in breast cancer.

Higher dose intensity can be delivered by escalating the doseper-cycle or by reducing the intervals between cycles, known as dose density [3]. This review discusses the rationale for and the results of clinical research focusing on a dose-dense strategy as a means of improving dose intensification, and the outcomes in operable breast cancer.

\section{Rationale for Intensifying Doses beyond the Standard}

\section{Evidence for a Dose-Response Relation in Cancer Chemotherapy}

The dose-response relation of cancer chemotherapy drugs is especially useful if the dose-response curve is steep, as this helps establish the minimum effective antitumor dose. A particularly steep dose-response curve has been postulated in adjuvant chemotherapy to explain why it is generally more effective than chemotherapy for advanced disease [4].

In vivo data show that there is a steep dose-response curve in drug-sensitive tumors. For example, a log-linear dose-response relation to single-dose cyclophosphamide has been shown in a murine model of various experimental tumors [4]. Thus, halving the dose could reduce tumor cell killing manyfold. In a clinical setting, this means that reducing the dose of chemotherapy could lead to ineffective treatment.

Milan's Instituto Nazionale Tumori's 20-year follow-up study of 386 women after radical mastectomy - half treated with cyclophosphamide, methotrexate, and fluorouracil adjuvant chemotherapy (CMF) and half treated with surgery only showed significantly higher disease-free (DFS) and overall survival (OS) in the CMF group [5]. Those who received at least $85 \%$ of the planned dose fared best.

A retrospective study by Mayers et al. also suggested that adjuvant chemotherapy with greater dose intensity increases survival in patients with breast cancer [6]. These investigators compared the results in patients who were treated with adjuvant chemotherapy for breast cancer with either classic 28-day CMF or less dose-intense, all-intravenous, 21-day CMF. Survivability trended upwards with 28-day CMF, leading the authors to recommend this regimen over the 21-day regimen.

A dose-response relationship has also been suggested in a prospective study testing three dose schedules of a combination of cyclophosphamide, doxorubicin, and fluorouracil (CAF) in 1550 patients [7]. High and moderate dose-intense regimens in the standard dose range were found to result in significantly greater DFS $(p<0.0001)$ and OS $(p=0.004)$ than a low-dose regimen after a median 9 -year follow-up. Another way of looking at this study is that the low-dose arm failed to achieve a minimum dosage threshold to be effective.

Therefore, standard-dose, on-schedule chemotherapy appears to be associated with better clinical outcomes in breast cancer than less dose-intense regimens.

\section{Scheduling Dose for Better Outcomes}

Two well-established hypotheses on tumor growth help to explain the value of dose intensification.

The Goldie-Coldman hypothesis addresses the spontaneous development of drug-resistant cells following exposure of the tumor to cytotoxic agents [8]. Drug-resistant mutations arise at a measurable frequency. The larger the tumor burden, the more likely a mutation will occur. This hypothesis predicts that early introduction of dose-intensive alternating agents is most likely to prevent a large number of resistant clones, increasing efficacy.

A basic premise of the Norton-Simon hypothesis is that 'chemotherapy results in a rate of regression of tumor volume that is proportional to the rate of growth for an unperturbed tumor that size' [9], that is, small tumors grow faster than larger ones. Nonexponential Gompertzian kinetics apply, which posit that cytoreductive therapy will lead to an increase in the regrowth between cycles. Subsequent chemotherapy must be delivered sequentially in the shortest possible intervals to be most effective [3]. In this Gompertzian model, the regrowth of cancer cells is a function of cytoreduction, such that the greater the tumor cell killing, the faster is the regrowth.

Thus, there is a clear rationale for increasing the dose intensity of chemotherapy, and this has driven clinical trials in adjuvant chemotherapy for breast cancer for the past three decades.

\section{Sequential Dosing}

Sequential, consecutive dosing of an agent, or a combination of agents, increases the dose density over alternating dosing, by targeting sensitive tumor cells with higher intensity before the onset of resistance [3].

The earliest proof of principle for the benefit of repetitive sequential treatment was from a randomized trial by Bonadonna and colleagues [10]. The investigators compared a sequential and an alternating schedule of doxorubicin and CMF in 403 women with breast cancer involving four or more axillary nodes. At a median follow-up of 10 years, DFS and OS were significantly greater with the sequential regimen: $42 \%$ vs. $28 \%$ ( $\mathrm{p}=0.002)$ and $58 \%$ vs. $44 \%(\mathrm{p}=0.002)$, respectively. Median DFS was 86 months after sequential chemotherapy and only 47 months after alternating chemotherapy. Median OS had not been reached after 10 years in the sequential-chemotherapy group and was 7.3 years in the alternating-chemotherapy group. The benefit of sequential over alternating chemotherapy was evident in all patients regardless of menopausal status, number of positive nodes, tumor size, or estrogen receptor status. The superior results were credited to sequential dose density, even though the total dose of each drug was the same with each schedule. 


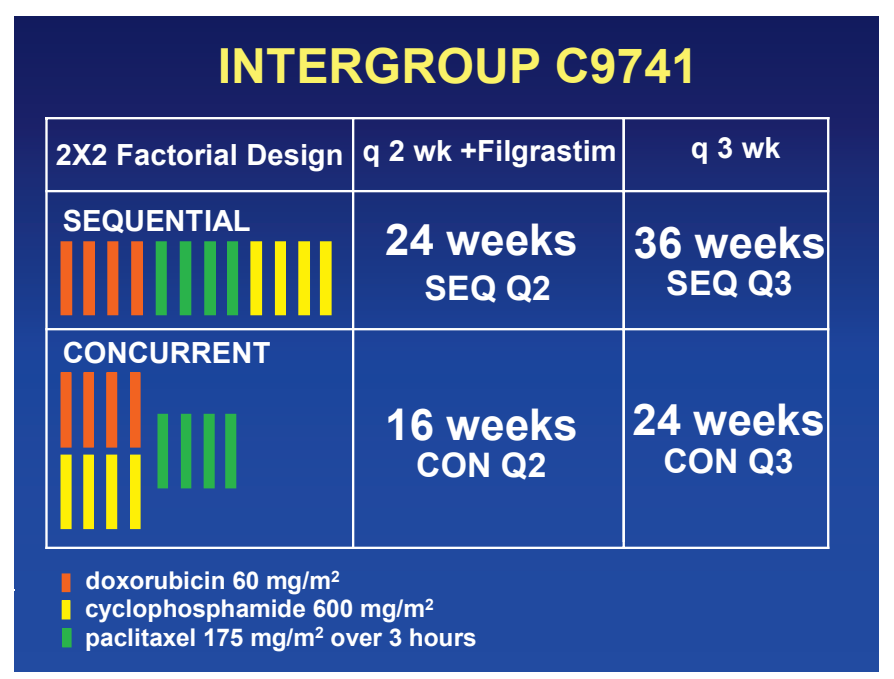

Fig. 1. C9741 treatment scheme.

Trials of Dose-Dense Regimens with Shorter than Standard Cycle Intervals

Recent studies of dose-dense regimens with shortened intertreatment intervals relative to a standard cycle fall into two categories, those testing one variable and those with multiple variables.

The true test of the dose density concept compares the same agents, at the same doses, but at different schedules. Only two adjuvant breast cancer trials, CALGB 9741 [11] and the Gruppo Oncologico Nord-Ovest-Mammella InterGruppo study (GONO-MIG-1) [12,13], isolate schedule, maintaining dosage and other treatment variables.

Trials that change dosage or other treatment variables in addition to the inter-treatment interval, such as AGO [14] and NCIC MA.21 [15], are more difficult to interpret.

The patient population is also an important consideration because the Norton-Simon hypothesis predicts that dose density will be most effective in situations with low-volume microscopic residual disease.

\section{CALGB 9741 and GONO-MIG-1: Trials Specifically Testing Dose Density}

Intergroup C9741/CALGB 9741 was a prospective randomized trial that tested the dose density with chemotherapy doses that could be used in the outpatient setting [11]. In a $2 \times 2$ design, this study compared sequential doxorubicin, paclitaxel, and cyclophosphamide $(\mathrm{A} \rightarrow \mathrm{T} \rightarrow \mathrm{C})$ with concurrent doxorubicin and cyclophosphamide followed by paclitaxel $(\mathrm{AC} \rightarrow \mathrm{T})$, using a dose-dense $(\mathrm{q} 14 \mathrm{~d})$ and a conventional (q21d) schedule (fig. 1). The dose-dense arms included daily injections of filgrastim beginning $72 \mathrm{~h}$ after the completion of the chemotherapy in each cycle (day 3) and continuing for 7 days. The median follow-up in the 1973 patients for the first report was 3 years.

DFS and OS were significantly greater with the dose-dense regimens (risk ratio $=0.74 ; \mathrm{p}=0.010$, and $0.69 ; \mathrm{p}=0.013$, respectively) and were not affected by the number of positive nodes, tumor size, menopausal status, or tumor estrogen receptor status. Treatment sequence was not correlated with DFS or OS. There was no interaction between dose density and treatment sequence.

The greater efficacy of dose-dense chemotherapy was not compromised by increased toxicity. Grade 3 or 4 neutropenia was significantly more common with conventional therapy than with dose-dense therapy (33\% vs. $6 \%$; p < 0.0001), and cycle delays due to neutropenia were significantly more frequent with conventional than with dose-dense therapy $(38 \%$ vs. $15 \%$; $<<0.0001)$. These favorable results were attributed to filgrastim prophylaxis with the dose-dense regimen.

The second report of C9741 indicated continued benefit in DFS and OS after 6.5 years of median follow-up [16]. A retrospective analysis suggested that dose-dense chemotherapy produced greater benefit for patients with receptor-negative than receptor-positive cancers. This finding has been controversial. Berry reported similar results in a retrospective analysis of two prior, consecutive CALGB adjuvant studies [17]. In contrast, there was no difference in chemotherapy benefit by receptor status in the most recent Oxford overview [18]. Also at 9.1 years of follow-up, a $0.7 \%$ incidence of acute myeloid leukemia/myelodysplastic syndrome (AML/MDS) in the dose-dense and conventional arms of C9741 indicates no increased risk with the use of filgrastim.

The second pure study of dose density was the GONO-MIG-1 trial reported by Venturini $[12,13]$. Although the study did not reach the planned accrual of 1400 women, it randomized 1214 patients with node-positive or high-risk node-negative disease to six courses of fluorouracil at $600 \mathrm{mg} / \mathrm{m}^{2}$, epirubicin at 60 $\mathrm{mg} / \mathrm{m}^{2}$, and cyclophosphamide $600 \mathrm{mg} / \mathrm{m}^{2}$ (FEC) every 14 days (FEC14) or 21 days (FEC21). At a median follow-up of 10.4 years, dose-dense FEC14 did not significantly improve OS, the study's primary per-protocol endpoint. With lower accrual and fewer relapses than anticipated, the statistical power to compare the arms was diminished.

In unplanned subgroup analyses, FEC14 was superior for receptor-negative, highly proliferating, and Her-2-positive cancers. In Her-2-positive patients, OS was 79\% (95\% confidence interval $(\mathrm{CI})=68-91 \%)$ with $\mathrm{FEC14}$ and $60 \%(95 \% \mathrm{CI}=$ 44-76\%) with FEC21. According to the Norton-Simon hypothesis, rapidly growing malignancies are the subgroups that should benefit specifically from dose-dense chemotherapy. Results of the GONO-MIG-1 trial have been interpreted as being primarily compatible with C9741 [19].

Similar to C9741, there was less leukopenia with FEC14. There were no cases of AML/MDS in either arm. FEC14 was associated with greater asthenia than FEC21. 


\section{Two Multiple-Variable Trials Compare Dose-Dense to Comparator Arms}

The German AGO-Trial and Canadian NCIC MA.21 Trials compare dose-dense chemotherapy to comparator arms using different drugs or dosages. AGO randomized 1284 women with four or more involved axillary nodes to three consecutive cycles of sequential epirubicin $150 \mathrm{mg} / \mathrm{m}^{2}$, paclitaxel $225 \mathrm{mg} /$ $\mathrm{m}^{2}$, and cyclophosphamide $2500 \mathrm{mg} / \mathrm{m}^{2}(\mathrm{E} \rightarrow \mathrm{T} \rightarrow \mathrm{C})$ every $2 \mathrm{wk}$ or to 4 cycles of EC $\left(90 / 600 \mathrm{mg} / \mathrm{m}^{2}\right)$ followed by 4 cycles of $\mathrm{T}\left(175 \mathrm{mg} / \mathrm{m}^{2}\right.$ every $\left.3 \mathrm{wk}\right)$. Dose-dense $\mathrm{E} \rightarrow \mathrm{T} \rightarrow \mathrm{C}$ improved relapse-free survival (RFS) $(70 \%$ vs. $62 \%, \mathrm{p}=0.00079)$ and OS $(82 \%$ vs. $77 \%, p=0.029)$ at a median follow-up of 62 months. Sequential $\mathrm{E} \rightarrow \mathrm{T} \rightarrow \mathrm{C}$ was associated with greater toxicity, including more emesis and a $7 \%$ rate of febrile neutropenia compared to $2 \%$ in $\mathrm{EC} \rightarrow \mathrm{T}, \mathrm{p}<0.0001$.

Individual doses of sequential $\mathrm{E} \rightarrow \mathrm{T} \rightarrow \mathrm{C}$ were higher than used in C9741. For doxorubicin and cyclophosphamide, dose levels greater than $60 \mathrm{mg} / \mathrm{m}^{2}$ and $600 \mathrm{mg} / \mathrm{m}^{2}$ were not more effective in prior adjuvant trials by the CALGB and NSABP $[20,21]$. Likewise, paclitaxel doses greater than $175 \mathrm{mg} / \mathrm{m}^{2}$ were not more effective in metastatic disease [22]. It is, therefore, difficult to assess whether the improved outcome is due to the shortened inter-treatment interval, the dose escalation, or their combination.

This lack of benefit from dose escalation in CALGB and NSABP suggests that dose density contributed to AGO's overall benefit.

The Canadian MA-21 trial had three adjuvant chemotherapy arms: (1) dose-dense epirubicin $100 \mathrm{mg} / \mathrm{m}^{2}$ and cyclophosphamide $600 \mathrm{mg} / \mathrm{m}^{2}$ for six 14-day cycles followed by paclitaxel for four 21-day cycles; (2) CEF for 6 cycles every $3 \mathrm{wk}$; and (3) doxorubicin and cyclophosphamide for 4 cycles followed by 4 cycles of paclitaxel, each cycle at 3 -wk intervals. At 30.4 months of median follow-up, dose-dense $\mathrm{EC} \rightarrow \mathrm{T}$ and $\mathrm{CEF}$ were statistically equivalent and superior to $\mathrm{AC} \rightarrow \mathrm{T}$, despite a fourfold higher rate of thromboembolic events. In the CEF arm, a disturbingly high rate of $22.9 \%$ febrile neutropenia was observed. Dose-dense $\mathrm{EC} \rightarrow \mathrm{T}$ had a $16.7 \%$ incidence of febrile neutropenia, much higher than C9741. A 4.8\% febrile neutropenia rate was significantly less for $\mathrm{AC} \rightarrow \mathrm{T}$. More detailed reporting of follow-up and toxicity will be necessary to fully evaluate this study. The multiple variables in this study cloud interpretation of the data.

\section{Future Perspectives}

The positive results in CALGB 9741 have influenced the design of ongoing and planned trials of adjuvant chemotherapy in node-negative and node-positive breast cancer.
NSABP-B38, a three-armed study comparing dose-dense $\mathrm{AC} \rightarrow \mathrm{T}$, dose-dense $\mathrm{AC} \rightarrow \mathrm{TG}$ (with gemcitabine added to paclitaxel) and 6 cycles of TAC (docetaxel, doxorubicin, and cyclophosphamide) has completed accrual. CALGB 40101, a trial with node-negative patients or patients with 1-3 positive nodes, incorporates dose density comparing 4 cycles of AC every 14 days vs. 4 cycles of paclitaxel every 14 days. Of interest is the back-to-basics testing protocol utilizing only singleagent paclitaxel.

In node-positive disease, US Intergroup trial S0221 compares dose-dense doxorubicin and cyclophosphamide every 14 days for 6 cycles ( 2 more cycles than in C9741) with pegfilgrastim support versus a metronomic regimen with continuous doxorubicin and cyclophosphamide and same-day filgrastim. Another comparison here is sequential paclitaxel given as it was in C9741 (175 mg/m² q14d) for 6 cycles -2 more cycles than in C9741 - versus paclitaxel $80 \mathrm{mg} / \mathrm{m}^{2} / \mathrm{wk}$ for $12 \mathrm{wk}$.

Because of its dose-dense/dose-intense approach, the German Adjuvant Intergroup Node-positive-GAIN Study, involving over 3000 patients, is widely anticipated by the oncologic community.

Biologics have been integrated into dose-dense regimens. Dang reported the cardiac safety of trastuzumab with dosedense $\mathrm{AC} \rightarrow \mathrm{T}$ in 70 patients with Her-2-positive disease [23]. Although well tolerated, the small study cohort of only 11 women over the age of 60 raises issues regarding the robustness of the favorable cardiac toxicity results.

Further developments in this area include using bevacizumab with dose-dense $\mathrm{AC} \rightarrow \mathrm{T}$ or $\mathrm{T}$ alone [24].

The future of adjuvant breast cancer therapy is treatment by molecular subtype, defined by gene profiles and tissue markers. Differing degrees of benefit from dose-dense chemotherapy will be experienced by these patient groups.

\section{Dose-Dense Chemotherapy Is Now a Leading Treatment Option}

Though more standard in the United States for treatment of node-positive disease [25], dose-dense adjuvant chemotherapy has become an internationally recognized option [26].

\section{Conclusion}

The dose density of adjuvant chemotherapy is an important predictor of the clinical outcome and has become widely used in the treatment and research of breast cancer. 


\section{References}

1 Hryniuk WM: The importance of dose intensity in the outcome of chemotherapy. Important Adv Oncol 1988;121-141.

$>2$ Hryniuk W, Frei E, 3rd, Wright FA: A single scale for comparing dose-intensity of all chemotherapy regimens in breast cancer: summation dose-intensity. J Clin Oncol 1998;16:3137-3147.

3 Norton L: Evolving concepts in the systemic drug therapy of breast cancer. Semin Oncol 1997;24 (suppl 10):S10-3-S10-10.

4 Frei E, 3rd, Canellos GP: Dose: A critical factor in cancer chemotherapy. Am J Med 1980;69:585-594.

5 Bonadonna G, Valagussa P, Moliterni A, Zambett M, Brambilla C: Adjuvant cyclophosphamide, methotrexate, and fluorouracil in node-positive breast cancer: the results of 20 years of follow-up. N Engl J Med 1995;332:901-906.

6 Mayers C, Panzarella T, Tannock IF: Analysis of the prognostic effects of inclusion in a clinical trial and of myelosuppression on survival after adjuvant chemotherapy for breast carcinoma. Cancer 2001; 91:2246-2257.

7 Budman DR, Berry DA, Cirrincione CT, Henderson IC, Wood WC, Weiss RB, Ferree CR, Muss HB, Green MR, Norton L, Frei E, 3rd: Dose and dose intensity as determinants of outcome in the adjuvant treatment of breast cancer. The Cancer and Leukemia Group B. J Natl Cancer Inst 1998;90: $1205-1211$.

8 Coldman AJ, Goldie JH: Impact of dose-intense chemotherapy on the development of permanent drug resistance. Semin Oncol 1987;14(suppl 4): 29-33.

9 Simon R, Norton L: The Norton-Simon hypothesis: designing more effective and less toxic chemotherapeutic regimens. Nat Clin Pract Oncol 2006;3: 406-407.

10 Bonadonna G, Zambetti M, Valagussa P: Sequential or alternating doxorubicin and CMF regimens in breast cancer with more than three positive nodes. Ten-year results. JAMA 1995;273:542-547.

11 Citron ML, Berry DA, Cirrincione C, Hudis C, Winer EP, Gradishar WJ, Davidson NE, Martino S Livingston R, Ingle JN, Perez EA, Carpenter J, Hurd D, Holland JF, Smith BL, Sartor CI, Leung EH, Abrams J, Schilsky RL, Muss HB, Norton L: Randomized trial of dose-dense versus conventionally scheduled and sequential versus concurren combination chemotherapy as postoperative adjuvant treatment of node-positive primary breast cancer: first report of Intergroup Trial C9741/Cancer and Leukemia Group B Trial 9741. J Clin Oncol 2003;21:1431-1439.
12 Venturini M, Del Mastro L, Aitini E, Baldini E, Caroti C, Contu A, Testore F, Brema F, Pronazto P, Cavazzini G, Sertoli M, Canavese G, Rosso R, Bruzzi P: Dose-dense adjuvant chemotherapy in early breast cancer patients: Results from a randomized trial. J Natl Cancer Inst 2005;97:17241733.

13 Del Mastro L, Bruzzi P, Nicolo G, Contu A, D'Amico M, Lavarello A, Testore F, Catagneto B, Aitini E, Perdelli L, Bighin C, Rosso R, Venturini M: HER-2 expression and efficacy of dose-dense anthracycline containing adjuvant chemotherapy in breast cancer patients. Br J Cancer 2005;93:7-14

14 Moebus VJ, Lueck HJ, Thomssen C, Kuhyn W, Kurbacher CV, Nitz U, Kreienberg R, Untch M, Jackisch C, Schneeweiss A, Huober J, du Bois A: Dosedense sequential chemotherapy with epirubicin, (E), paclitaxel (T), and cyclophosphamide C (ETC) in comparison to conventional dosed chemotherapy in high risk breast cancer patients $(\geq 4 \mathrm{LN})$. Mature results of an AGO trial. In San Antonio Breast Cancer Symposium, San Antonio 2006

15 Burnell M, Levine M, Chapman JA, Bramwell V, Gelmon K, Walley B, Whelan T, Albain K, Perez E, Rugo H, Ding Z, O'Brien P, Shepherd L, Pritchard $\mathrm{K}$ : A randomized trial of CEF versus dose dense EC followed by paclitaxel versus AC followed by paclitaxel in women with node positive or high risk node negative breast cancer, NCIC CTG MA.21: Results of an interim analysis. In San Antonio Breast Cancer Symposium, San Antonio, 2006.

16 Hudis C, Citron M, Berry D, Cirrincione C, Gradishar W, Davidson N, Martino S, Livingston R, Ingle J, Perez E, Abrams J, Schilsky R, Ellis M, Muss H, Norton L, Winer E: Five year follow-up of INT C9741: dose-dense (DD) chemotherapy (CRx) is safe and effective. In San Antonio Breast Cancer Symposium, San Antonio 2005.

17 Berry D, Cirrincione C, Henderson C, Citron M, et al.: Estrogen-receptor status and outcomes of modern chemotherapy for patients with node-positive breast cancer. JAMA 2006;25:1658-1667.

18 Peto R for the Early Breast Cancer Trialists' Collaborative Group: The worldwide overview: new results for systemic adjuvant therapies. In San Antonio Breast Cancer Symposium, San Antonio 2007.

19 Lin N, Gelman R, Winer E: Dose density in breast cancer: A simple message? J Natl Cancer Inst 2005; 97:1712-1714.
20 Henderson IC, Berry DA, Demetri GD, Cirrincione CT, Goldstein LJ, Martino S, Ingle JN, Cooper MR, Hayes DF, Tkaczuk KH, Fleming G, Holland JF, Duggan DB, Carpenter JT, Frei E, 3rd, Schilsky RL, Wood WC, Muss HB, Norton L: Improved outcomes from adding sequential paclitaxel but not from escalating doxorubicin dose in an adjuvant chemotherapy regimen for patients with node-positive primary breast cancer. J Clin Oncol 2003;21: 976-983.

21 Fisher B, Anderson S, DeCillis A, Dimitrov N, Atkins JN, Fehrenbacher L, Henry PH, Romond EH, Lanier KS, Davila E, Kardinal CG, Laufman L, Pierce HI, Abramson N, Keller AM, Hamm JT, Wickerham DL, Begovic M, Tan-Chiu E, Tian W, Wolmark N: Further evaluation of intensified and increased total dose of cyclophosphamide for the treatment of primary breast cancer: Findings from the National Surgical Adjuvant Breast and Bowl Project. B-25. J Clin Oncol 1999;17:3374-3388.

22 Winer E, Berry DA, Woolf S, Duggan D, Kornblith A, Harris LN, Michaelson RA, Kirshner JA, Fleming GF, Perry MC, Graham ML, Sharp SA, Keresztes R, Henderson IC, Hudis C, Muss H, Norton L: Failure of higher-dose paclitaxel to improve outcome in patients with metastatic breast cancer: Cancer and Leukemia Group B trial 9342. J Clin Oncol 2004;22:2061-2068.

23 Dang C, Fornier M, Sugarman S, Toso-Sandaval T, Lake D, D'Andrea G, Seidman A, Sklarin N, Dickler M, Currie V, Gilewski T, Moynahan M, Drulinsky P, Robson M, Wasserheit-Leiblich C, Mills N, Steingart R, Panageas K, Norton L, Hudis C: The safety of dose-dense doxorubicin and cyclophosphamide followed by paclitaxel with trastuzumab in Her-2/neu overexpressed/amplified breast cancer. J Clin Oncol 2008;26:1216-1222.

24 Miller K, O’Neill A, Perez E, Seidman A, Sledge G: Phase II feasibility trial incorporating bevacizumab into dose dense doxorubicin and cyclophosphamide followed by paclitaxel in patients with lymph node positive breast cancer: A trial of the Eastern Cooperative Oncology Group (E2104). J Clin Oncol 2008;26(suppl):abstr 520.

25 Hudis C, Carlson R: Adjuvant chemotherapy. Patterns Care Med Oncol 2007;4:1-4.

26 Untch M: Dose-dense therapy. Breast Care 2008;3: 134-138. 